\title{
Surgery with hyperthermic intraperitoneal chemotherapy after response to induction chemotherapy in patients with peritoneal metastasis of gastric cancer
}

\author{
Emel Canbay $^{1 \wedge}$, Bahar Canbay Torun ${ }^{2}$, Kaan Cosarcan $^{3}$, Cetin Altunal ${ }^{1}$, Bulent Gurbuz ${ }^{4}$, Cagri Bilgic ${ }^{4}$, \\ Canfeza Sezgin $^{5}$, Kerim Kim Kaban ${ }^{6}$, Serpil Yilmaz ${ }^{7}$, Zeliha Yazici ${ }^{8}$ \\ ${ }^{1}$ Department of General Surgery, NPO Center for Peritoneal Surface Malignancies, Istanbul, Turkey; ${ }^{2}$ Department of General Surgery, Istanbul Haseki \\ Education \& Research Hospital, Istanbul, Turkey; ${ }^{3}$ Department of Anesthesiology, American Hospital, Istanbul, Turkey; ${ }^{4}$ Department of General \\ Surgery, American Hospital, Istanbul, Turkey; ${ }^{5}$ Department of Medical Oncology, American Hospital, Istanbul, Turkey; ${ }^{6}$ Department of Medical \\ Oncology, Faculty of Medicine, Biruni University, Istanbul, Turkey; ${ }^{7}$ Department of Pathology, American Hospital, Istanbul, Turkey; ${ }^{8}$ Department of \\ Pharmacology, Faculty of Medicine, Biruni University, Istanbul, Turkey \\ Contributions: (I) Conception and design: E Canbay; (II) Administrative support: E Canbay, Z Yazici; (III) Provision of study materials or patients: \\ All authors; (IV) Collection and assembly of data: B Canbay Torun, K Cosarcan, C Altunal, B Gurbuz, C Bilgic, K Kim Kaban, S Yilmaz; (V) Data \\ analysis and interpretation: E Canbay, S Yilmaz, C Sezgin; (VI) Manuscript writing: All authors; (VII) Final approval of manuscript: All authors. \\ Correspondence to: Emel Canbay, MD, PhD. Professor of General Surgery, Department of General Surgery, NPO Center for Peritoneal Surface \\ Malignancies, Istanbul, Turkey. Email: drecanbay@gmail.com.
}

Background: Gastric cancer (GC) with peritoneal metastases (PM) has a dismal prognosis and to date only a few management options have been reported. Of those, cytoreductive surgery (CRS) and hyperthermic intraperitoneal chemotherapy (HIPEC) after induction bidirectional intraperitoneal and systemic chemotherapy (BIPSC) appear as a promising treatment option for these patients. Outcome data including safety and efficacy of CRS with radical Gastrectomy and HIPEC after response to combination of laparoscopic HIPEC (LHIPEC) with BIPSC as an induction therapy in patients with PM of GC was evaluated in this retrospective observational study.

Methods: Diagnostic Laparoscopy was performed in 53 patients with PM of GC who admitted to the Center for Treatment of Peritoneal Surface Malignancies, Istanbul, between 2013 and 2016. Peritoneal cancer index (PCI), ascites status and cytology were determined. The patients underwent LHIPEC and then, BIPSC induction chemotherapy using intraperitoneal docetaxel $\left(30 \mathrm{mg} / \mathrm{m}^{2}\right)$ and cisplatin $\left(30 \mathrm{mg} / \mathrm{m}^{2}\right)$ and intravenous Docetaxel/Cisplatin/5-Fluorouracil (DCF) for 3 cycles. In selected patients, CRS with radical gastrectomy and HIPEC were performed after the response to induction therapy. BIPSC was continued for 3 more cycles with a dose reduction in an adjuvant setting.

Results: All LHIPEC procedures were uneventful with Grade 1-2 side effects (11/53, 20,8\%). As a response to induction chemotherapy PCI was reduced from $19.6 \pm 8$ (range, 6-39) to 13.6 \pm 9.8 (range, 1-39) $(\mathrm{P}<0.001)$. Ascites was detected in 55\% (29 out of 53) and cytology was positive in $51 \%$ (27 out of 53) of the patients before induction chemotherapy. Ascites was completely abolished and all cytology became negative. Then, 34 of $53(64.15 \%)$ patients underwent CRS with radical gastrectomy and HIPEC. CC0/1 resection was achieved in $22(64.70 \%)$ of patients $(\mathrm{P}<0.05)$. The median survival time was $18.9 \pm 13.4(95 \% \mathrm{CI}: 15.2-$ 22.6 months. Combined surgery and HIPEC related mortality occurred in 1 out of 34 patients (2.9\%) due to developed diffuse intravascular coagulation at postoperative day 2. Grade 2 operative complications included biliary fistula in one, and duodenal stump leakage in two patients (8.7\%). All of the fistula closed with conservative management. The median survival time was $18.9 \pm 13.4$ months and the median progression-free survival time was $15.6 \pm 12.9$ with 1 -, 2 -, and 5-year survival rates of $82.4 \%, 59 \%$ and $17.6 \%$ in patients with

$\wedge$ ORCID: 0000-0001-7592-3000. 
PM of GC. Multivariate analysis identified high peritoneal cancer index $(\mathrm{P}=0.000)$ and complete resection $(\mathrm{P}<0.05)$ as independent predictors for better progression-free and overall survival.

Conclusions: The best outcomes can be expected with optimal cytoreduction and limited peritoneal dissemination in response to induction chemotherapy. Knowledgeable selection of patients with PM of GC is essential to perform surgery with HIPEC safely with acceptable mortality and morbidity.

Keywords: Surgery; hyperthermic intraperitoneal chemotherapy (HIPEC); peritoneal metastasis; gastric cancer (GC); induction chemotherapy; laparoscopy; laparoscopic hyperthermic intraperitoneal chemotherapy (laparoscopic HIPEC)

Submitted Feb 21, 2020. Accepted for publication Aug 25, 2020.

doi: 10.21037/jgo-20-121

View this article at: http://dx.doi.org/10.21037/jgo-20-121

\section{Introduction}

The prognosis of GC patients with PM is poor and survival is limited to several months $(1,2)$. To date, four different strategies for management of PM of GC are currently in use worldwide. The first standard of care for the patients with PM of GC is systemic chemotherapy to achieve control of PM or best supportive care suggested by National Comprehensive Cancer Network (NCCN) guidelines (3). NCCN Guidelines also accept that positive peritoneal cytology during staging laparoscopy or laparotomy is classified as having Stage IV incurable disease (3). If the disease appears to be controlled by radiological evaluation in response to systemic chemotherapy, surgery may be performed to relieve symptoms such as intestinal obstruction in a palliative setting.

A second option is CRS (4) with radical gastrectomy and HIPEC (5). This strategy has been shown to improve survival in a randomized controlled trial (6).

A third approach published by our group presents the outcomes of response to bidirectional intraperitoneal and systemic induction chemotherapy (BIPSC) followed by CRS and HIPEC from 194 patients with PM of GC in 2014 (7). Our results indicated that BIPSC allows one to perform CRS and HIPEC. With complete cytoreduction, prolonged life and even cure of these patients with acceptable morbidity and mortality was reported. Median survival was 18 months. Of those patients who had a CRS and HIPEC, median survival was 15.8 months. More recently, the results of this approach to treatment without HIPEC have been published by Ishigami and his multi-institutional team (8).

The best outcomes in cancer treatments only occur with complete resection. Therefore, to downstage the "Peritoneal Cancer Index (PCI)" (9) or in another words "reduce tumor burden" is an important step to achieve complete cytoreduction for longer survival and even cure of these patients.

A fourth approach is focused on a decreased tumor burden as measured by a reduced PCI using induction chemotherapy administered as LHIPEC (10). Then LHIPEC, in conjunction with BIPSC, was introduced in order to prolong survival as a consequence of decreased tumor burden and reduced ascites formation and to obtain a cytology free from cancer cells (11). Our previous results supported that LHIPEC, (I) had a direct effect on ascites in patients with PM of GC, (II) had a direct effect on positive cytology and (III) had an effect to downsize the tumor.

Here, we report outcome data of surgery with radical gastrectomy and HIPEC after response to LHIPEC and BIPSC induction therapy in patients with PM of GC. Treatment was completed by applying three cycles of BIPSC in an adjuvant setting. We present the following article in accordance with the STROBE Reporting Checklist (available at http://dx.doi.org/10.21037/jgo-20-121).

\section{Methods}

\section{Patients}

Fifty-three patients with GC admitted to Peritoneal Surface Malignancy Center in Istanbul underwent diagnostic laparoscopy between April 2013 and January 2017. Patients eligible for treatments had (I) a PM of GC confirmed by histopathology, (II) absence of extra-abdominal metastasis and liver metastasis, (III) performance status [(Eastern Cooperative Oncology Group (ECOG)] 22, (IV) PM were considered as synchronous to the primary tumor if it was diagnosed within 6 months even if patients had prior surgery without GC surgery and systemic chemotherapy 
for GC. The study was conducted in accordance with the Declaration of Helsinki (as revised in 2013). The study was approved by institutional ethics board of Biruni University and informed consent was taken from all the patients.

\section{Laparoscopic HIPEC}

Initially, diagnostic laparoscopy was performed and peritoneal biopsy along with peritoneal washing for cytology and ascites' samples were taken to confirm diagnosis. Peritoneal Cancer Index (PCI) was (9) calculated prior to LHIPEC procedure. All LHIPEC procedures required a five-port technique. Two inflow catheters were placed to subdiaphragmatic spaces and two outflow catheters were placed at the Douglas pouch. HIPEC was performed intraperitoneally (IP) with docetaxel $\left(30 \mathrm{mg} / \mathrm{m}^{2}\right)$ and cisplatin $\left(30 \mathrm{mg} / \mathrm{m}^{2}\right)$ with a total volume of $1.5 \mathrm{~L} / \mathrm{m}^{2}$ of saline solution for 90 minutes with inflow temperature of $43^{\circ} \mathrm{C}$. Then, an intraperitoneal port catheter into the upper abdomen and systemic port catheters were placed before termination of the procedure.

\section{Bidirectional intraperitoneal systemic chemotherapy (BIPSC)}

Three cycles of BIPSC was initiated one week after LHIPEC as a neoadjuvant treatment. Also, every three weeks after cytoreductive surgery (CRS) and HIPEC in an adjuvant setting. BIPSC was a combination of Docetaxel/ Cisplatin/5-Fluororuracil (DCF) regimen given systemically plus docetaxel $\left(30 \mathrm{mg} / \mathrm{m}^{2}\right)$ with cisplatin $\left(30 \mathrm{mg} / \mathrm{m}^{2}\right)$ in a $500 \mathrm{~mL}$ saline solution administered IP.

\section{CRS and HIPEC procedure}

Radical Gastrectomy with peritonectomy procedures were performed in patients who responded to induction therapy. After surgery, extensive intraperitoneal lavage (EIPL) was performed as described previously (12). Surgical approach involves radical gastrectomy and D2 lymph node dissection (13), peritonectomy procedures and visceral resections as described by Sugarbaker (14) and Yonemura (15). The epigastric peritonectomy includes to excision of prior midline incision scar and underlying fatty tissue. Bilateral anterior parietal peritonectomy included Morrison's pouch and peritoneum of right and left paracolic gutter. Omental bursectomy included the peritoneum covering the hepatoduodenal ligament. Bilateral hemi- diaphragmatic peritonectomies were performed, if necessary. Cholecystectomy and appendectomy were also performed. If the tumors were within the cul-de-sac, pelvic peritonectomy with total abdominal hysterectomy and bilateral oophorectomy and rectosigmoid colon resection with anastomosis were included to the surgery.

HIPEC procedure was performed with closed technique. Two indwelling catheters were placed to right and left subdiaphragmatic areas and two outflow catheters were inserted into the Douglas pouch. HIPEC was performed with docetaxel $\left(30 \mathrm{mg} / \mathrm{m}^{2}\right)$ and cisplatin $\left(30 \mathrm{mg} / \mathrm{m}^{2}\right)$ with the chemoperfusate heated to achieve a temperature of $43{ }^{\circ} \mathrm{C}(7)$. As described by Van der Speeten et al., $260 \mathrm{mg} / \mathrm{m}^{2}$ of sodium-2-mercaptoethane sulfonate (MESNA) was administered as an intravenous bolus in $100 \mathrm{~mL}$ of $0.9 \% \mathrm{NaCl} 15$ minutes prior to intravenous initiation of ifosfamide, then repeated 4 and 8 hours later. An intravenous infusion of ifosfamide $\left(1,300 \mathrm{mg} / \mathrm{m}^{2}\right)$ in $1 \mathrm{~L}$ of $0.9 \% \mathrm{NaCl}$ was begun at the initiation of HIPEC and continued at a constant rate over the next 90 minutes (16). Ifosfamide with MESNA as a protective agent was used systemically for 90 minutes.

\section{Evaluation of treatment}

The patients' responses to BIPSC were evaluated according to response evaluation criteria in solid tumors (RECIST) criteria with computerized thoraco-abdominal tomography (CAT) scan and with tumor markers CEA, CA19-9, CA72-4, and CA 125 levels (17). The patients with good performance status were assessed by a second diagnostic laparoscopy if radiologic signs and tumor marker levels were clearly decreased or there was no clear evidence of progression. If PCI levels were decreased and washing cytology was free from cancer cells, the patients underwent CRS with radical gastrectomy and HIPEC procedure. PCI levels were calculated by the surgeon (E.C.) and the assistant for each case to address potential sources of bias

The same BIPSC protocol was restarted in three weeks after surgery for 3 cycles with appropriate dose reduction due to postoperative decrease in chemotherapy tolerance. Preoperative, perioperative and postoperative data were collected from electronic medical records. Followup was performed by surgeon and medical oncologists. The first evaluation of early outcome was 7 and 30 days morbidity and mortality after CRS and HIPEC procedures. Surgical complications were graded by the Clavien-Dindo classification system and reported as minor (Grade I and II), 
Positive cytology and ascites with peritoneal metastasis of HG-PSC

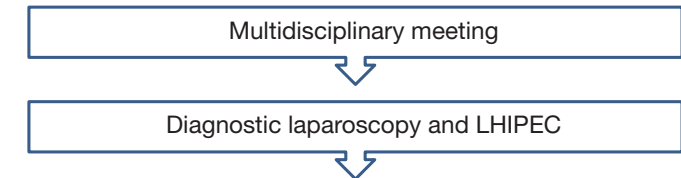

Neoadjuvant intraperitoneal and systemic chemotherapy $\times 3$

々 Negative cytology

Diagnostic re-laparoscopy and Cytoreductive Surgery and HIPEC

Adjuvant intraperitoneal and systemic chemotherapy $\times 3$

Follow-up

Figure 1 Proposed management algorithm of GC patients with cytology positive or with peritoneal metastases.

Table 1 Characteristics of the patients with PM of GC

\begin{tabular}{lll}
\hline Characteristics & $\begin{array}{l}\text { Number of patients } \\
(\mathrm{n}=53)\end{array}$ & $\%$ \\
\hline Age (years), median (range) & $51(29$ to 73$)$ & 100 \\
Sex & 20 & 38 \\
Male & 33 & 62 \\
Female & $11 \pm 10(1$ to 40$)$ & \\
Time from diagnosis to definitive & & \\
treatment (week) & & 30 \\
Previous surgery & 16 & 70 \\
Yes & 37 & \\
No & & 57 \\
Previous chemotherapy & 30 & 43 \\
Yes & 23 & 28.3 \\
No & 15 & 9.4 \\
Site of origin & & \\
Fundus & 5 & \\
Corpus & & \\
Antrum & & \\
\hline
\end{tabular}

major (Grade III and IV) and death (Grade V) (18). Adverse events related to chemotherapy drugs were classified according to Common Terminology Criteria for Adverse Events (CTCAE) version 5.0 defined by the National Cancer Institute (19).

The residual disease following CRS was classified intraoperatively using the completeness of cytoreduction (CC) scores (9). Pathological responses were evaluated according to the general rules for GC treatment.

\section{Statistical analysis}

The study size was calculated with power analysis. No patients were lost to follow up. Outcome data were obtained from medical records and patients' interviews. Results are presented as the median with range. The patients who underwent CRS and HIPEC and patients with no further surgery were compared by Fisher's exact test or Pearson's chi-square test. Univariate analysis was performed using the log-rank test, multivariate analysis was conducted using the Cox proportional hazards model. Overall survival was calculated by the method of Kaplan-Meier method from the initial date of the treatment to the occurrence of the event or to date of the most recent follow up visit. The overall survival rates were compared between groups of patients who underwent CRS and HIPEC after response to induction chemotherapy and those who did not have further surgery. The extent of peritoneal metastasis (PCI) and completeness of cytoreduction (CC) status was used to assess these groups. Results were compared with log-rank test. Statistical analysis was performed using SPSS 11.0 from Statistical Package for the Social Sciences Inc. software package.

\section{Results}

There were 20 male and 33 female patients with a mean age

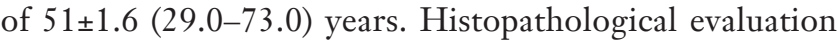
of PM of GC showed that poorly differentiated and signet ring cell carcinoma were dominant (50/53, 94.3\%). Our treatment algorithm for Management of Patients with PM of GC is shown in Figure 1. Of these patients, 16 of 53 patients $(30 \%)$ had previous surgery within 6 months and 30 of $53(57 \%)$ patients had previous cisplatin-based systemic chemotherapy for a median of 8 cycles. The patients' characteristics at the beginning of the treatment are presented in Table 1. 
Table 2 Response to induction chemotherapy was significant when evaluated by peritoneal cancer index decrease, regression of ascites and conversion to negative cytology

\begin{tabular}{llll}
\hline Characteristics & $\begin{array}{l}\text { Before Induction } \\
\text { chemotherapy }\end{array}$ & $\begin{array}{l}\text { After Induction } \\
\text { chemotherapy }\end{array}$ & P value \\
\hline $\mathrm{PCl}$ & 19.6 & 13.6 & 0.000 \\
Ascites & $29 / 53(54.7 \%)$ & Absent & 0.000 \\
Cytology & $27 / 53(50.9 \%)$ & Absent & 0.000 \\
\hline
\end{tabular}

\section{LHIPEC}

All 53 patients underwent to LHIPEC. At laparoscopy, peritoneal specimens were taken for confirmation of diagnosis. PCI was calculated as $19.6 \pm 8$ at the beginning of treatment varying between $6-39$. Ascites were detected in 29 out of 53 (55\%) and cytology was positive in 27 out of $53(51 \%)$ patients. Time between diagnosis and performance of LHIPEC was $11 \pm 10$ week. No patients were converted to laparotomy, all procedures were uneventful. Grade I-II toxicity following LHIPEC with no mortality was experienced. Patients are discharged 5 to 7 days postoperatively.

\section{Toxicity of bidirectional intraperitoneal and systemic chemotherapy (BIPSC)}

Adverse events were graded according to the National Cancer Institute-Common Terminology Criteria for Adverse Events Version 4. Hematologic complications were experienced in 2 patients (3.7\%) (leucopenia in 2 patients), diarrhea in $1(1.8 \%)$, fatigue in $4(7.5 \%)$ and emesis was experienced in $4(7.5 \%)$ patients. Renal failure was not detected in any of the patients in the induction therapy.

\section{Port-related complications}

Intraperitoneal port was placed subcutaneously in the lower abdomen. In a single patient the subcutaneous port was turned upside down and needed to be revised.

\section{Results of LHIPEC and BIPSC}

Sixteen out of 53 patients (31\%) had a previous surgery within 6 months. These patients were accepted as a synchronously peritoneal metastases (PM) for this study. Pathological diagnosis was confirmed as peritoneal metastasis of GC in all patients. Ascites resolved and cytology became negative in all 53 patients. Therefore, selection of patients for surgical intervention was made according to decrease in PCI levels, disease stability and patients' performance status. Table 2 shows the results of the patients who had the responses to induction chemotherapy

\section{CRS and HIPEC procedures}

Thirty-four of 53 patients $(66 \%)$ underwent total gastrectomy with D2 lymph node resection and peritonectomy procedures. Of those patients, 20 were female and 14 were male. Cytology was negative and ascites absent in these 34 patients. Pathological partial response less than $50 \%$ were detected in all patients. There were no complete responses or negative lymph nodes at final pathology report. Radical gastrectomy was performed with CRS. Splenectomy was added in 11 (34\%) cases due to heavily involvement of splenic hilum. Subtotal colon resection and segmental small bowel resections were performed in 6 patients (17.6\%). Perioperatively, no major complication was experienced and blood loss was minimal. Postoperative complications included gastrointestinal fistula in 3 patients and DIC in one patient. After surgery, 22 patients out of 34 patients $(64.7 \%)$ had no residual tumor $(\mathrm{CC} 0 / 1)$.

Mortality rate was $2.9 \%(1 / 34)$. The cause of death was disseminated intravascular coagulation (DIC) of unknown cause. The patient died on postoperative day 2. Grade II morbidity rate was $8.7 \%$. One had a bile fistula and two had leakage from the duodenal stump. There was acute kidney injury in 8 out of 35 patients (22.85\%) that resolved without intervention. Early postoperative hydration resolved the increased creatinine levels by postoperative day 4 . Median discharge day was day 12 and ranged between 9-20 days. Table 2 shows the characteristic of the patients underwent surgery or no surgery in response to induction chemotherapy.

\section{Survival rates}

Figure 2 shows the overall survival in patients who underwent surgery with HIPEC after induction chemotherapy and those who had induction chemotherapy alone. In 34 patients with response to LHIPEC and BIPSC, CRS with radical gastrectomy and HIPEC had significantly better overall survival than that those have no response to induction chemotherapy. The median survival time (MST) of 53 patients was $18.9 \pm 13.4$ months (95\% CI: 17.7-24.7 months). The patients' survival was categorized 


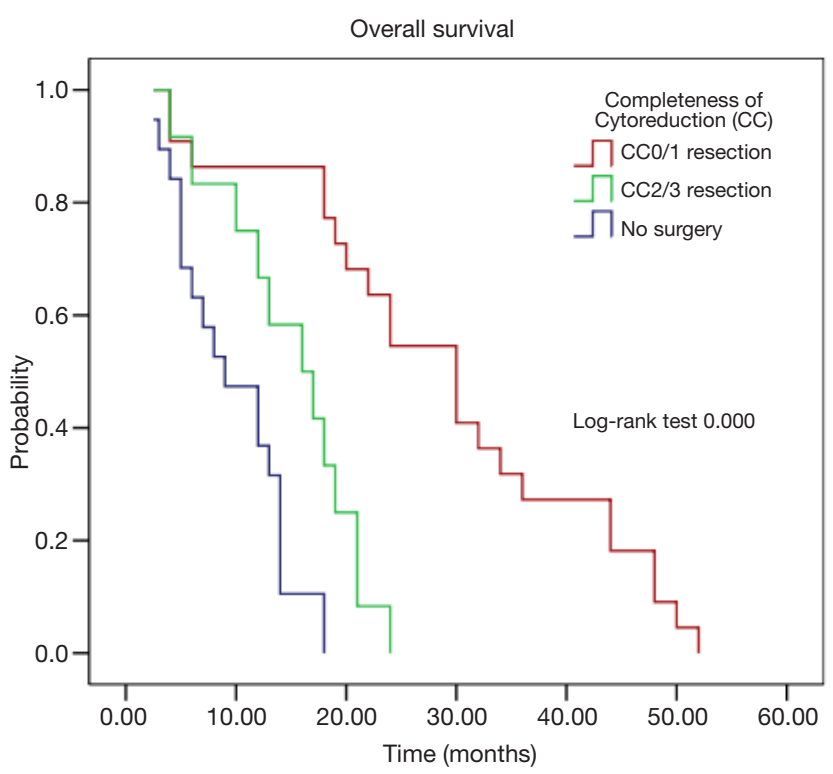

Figure 2 Kaplan-Meier curve for the overall survival of patients who underwent surgery with complete cytoreduction $(n=22)$, surgery with incomplete surgery $(n=12)$ and those who did not undergo surgery $(\mathrm{n}=19)(\log$-rank test $=0.000)$.

according to PCI levels and completeness of surgery. 268 patients with response to induction therapy who underwent CRS with radical gastrectomy and HIPEC had significantly better overall survival than those who did not have surgery (21.2 vs. 15.9 months with 1-, 2-, and 5-year survival rates of $82.4 \%$ vs. $59 \%, 17.6 \%$ vs. $52.6 \%, 26.3 \%$ vs. $0 \%$, respectively). Patients who had complete CRS (CC0/1) also had a significantly longer survival than those with CC2/3 resection $(\mathrm{P}<0.009)$ (Table 3, Figure 2). Patients with PCI $\leq 6$ had a longer survival than those with $\mathrm{PCI}>6(\mathrm{P}=0.000)$ (Table 3, Figure 3).

\section{Discussion}

In the current study, 34 out of $53(64.15 \%)$ patients with PM of GC underwent conversion surgery with HIPEC after response to induction chemotherapy. LHIPEC and aggressive surgery with more than 2 anastomoses in combination with HIPEC was performed safely. Twentytwo patients $(64.7 \%)$ had a CC0/1 resection. Six out of 34 (17.6\%) patients showed reach to 5-year survival (Table 2).

The median survival is limited to months without any treatment of patients with GC. Systemic chemotherapy is well established and recognized by NCCN as treatment of PM of GC. Although many chemotherapy trials have been
Table 3 Statistical comparison of the characteristics of the patients who underwent CRS and HIPEC after response to induction chemotherapy to pts with no further surgery

\begin{tabular}{|c|c|c|c|}
\hline Characteristics & $\begin{array}{l}\text { CRS and HIPEC } \\
\qquad(n=34)\end{array}$ & $\begin{array}{l}\text { No surgery } \\
\quad(n=19)\end{array}$ & $P$ value \\
\hline Age (years), median & $50.55 \pm 10.4$ & $50.1 \pm 14$ & 0.894 \\
\hline Sex & & & 0.564 \\
\hline Male & 14 & 6 & \\
\hline Female & 20 & 13 & \\
\hline $\begin{array}{l}\text { Time from diagnosis } \\
\text { to definitive treatment } \\
\text { (week) }\end{array}$ & $11 \pm 10$ (1 to 40$)$ & & \\
\hline Site of origin & & & 0.012 \\
\hline Fundus & 5 & 0 & \\
\hline Corpus & 10 & 5 & \\
\hline Antrum & 13 & 9 & \\
\hline Prepyloric & 6 & 5 & \\
\hline Previous surgery & & & 0.053 \\
\hline Yes & 4 & 12 & \\
\hline No & 30 & 7 & \\
\hline Previous chemotherapy & & & 0.085 \\
\hline Yes & 13 & 17 & \\
\hline No & 21 & 2 & \\
\hline CCR resection & & & NA \\
\hline CC0/1 resection & 22 & & \\
\hline CC2/3 resection & 12 & & \\
\hline No surgery & - & 19 & \\
\hline PCI prior LHIPEC & $19.6 \pm 8$ & $13.6 \pm 9$ & 0.000 \\
\hline \multicolumn{4}{|l|}{ Survival } \\
\hline 1-year & 28 & 10 & 0.000 \\
\hline 2-year & 20 & 5 & 0.000 \\
\hline 5-year & 6 & - & 0.000 \\
\hline
\end{tabular}

$\mathrm{PCl}$, peritoneal cancer index; CCR, completeness of cytoreduction; HIPEC, hypertermic intraoperative intraperitoneal chemotherapy; CRS, cytoreductive surgery; NA, not applicable.

studied for advanced GC, none of them give an optimal treatment with acceptable toxicity (20). Recently, studies based on the effects of surgery in response to induction chemotherapy have attracted surgical oncology groups.

One of those, the GYMSSA study, was a prospective 


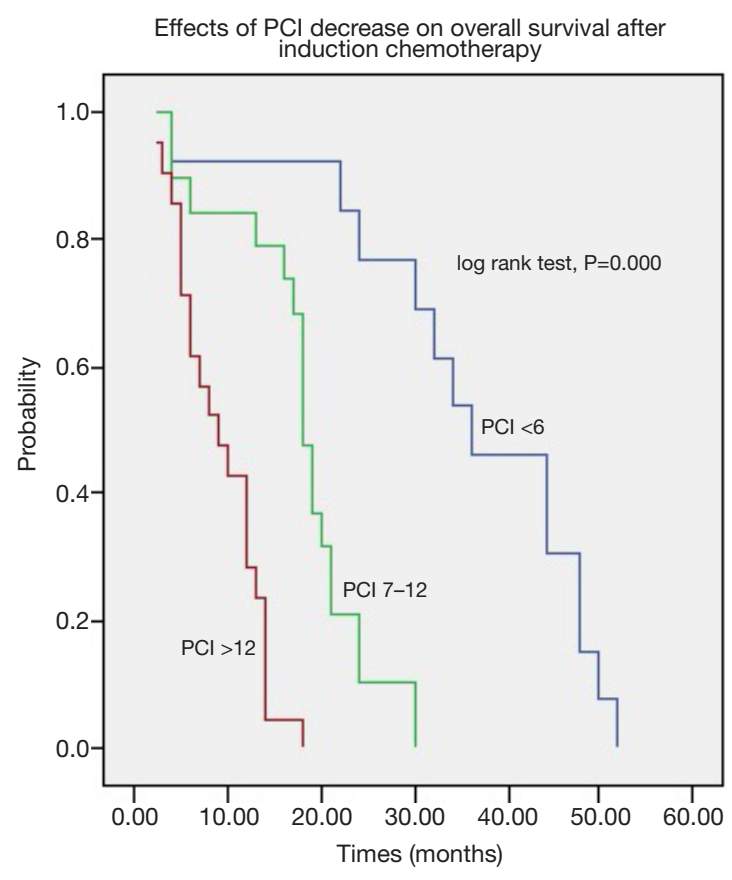

Figure 3 Kaplan-Meier curve by extent of disease (PCI levels) (log-rank test $=0.000)$. Effects of peritoneal cancer index $(\mathrm{PCI})$ on survival in 34 patients after CRS plus HIPEC.

randomized trial to compare a promising new systemic chemotherapy regimen to CRS with HIPEC followed by systemic chemotherapy for PM of GC (21). The systemic chemotherapy used in both arms was FOLFOXIRI (irinotecan, leucovorin, oxaliplatin, and 5-FU). Patients in the standard therapy arm were administered systemic chemotherapy every 14 days for 12 cycles. The patients in the second treatment arm (GYMSSA) underwent gastrectomy, metastasectomy of liver or lung if needed and HIPEC. HIPEC was administered with oxaliplatin $460 \mathrm{mg} / \mathrm{m}^{2}$ at $41^{\circ} \mathrm{C}$ for 30 minutes. Bidirectional treatment using 5 -FU $400 \mathrm{mg} / \mathrm{m}^{2}$ and leucovorin $20 \mathrm{mg} / \mathrm{m}^{2}$ was given just prior to perfusion to enhance the effects of intraperitoneal oxaliplatin. Patients were then started on FOLFOXIRI 8 weeks after surgery. Median survival in the systemic chemotherapy arm was 4.3 months and the GYMSSA arm 11.3 months with 4 of 9 (44\%) patients living longer than 12 months.

However, there is not an established role of surgery in PM of GC. Recently, REGETTA trial indicated that tumor burden reducing surgery with combination of chemotherapy was also not superior to chemotherapy alone in advanced GC cases (22).

In comparison to these results, conversion surgery after response to bidirectional chemotherapy was performed in GC patients with PM or positive cytology by Ishigami and his colleagues (23). Their results showed that surgery was safe with longer survival. Then, Okabe and colleagues (24) reported that bidirectional chemotherapy using S-1 with cisplatin had a response rate $57.9 \%$ of the patients with PM of GC. These studies provide the rationale of our studies that use direct application of chemotherapy into the peritoneal space. Previously, we reported that the bidirectional chemotherapy with cisplatin and docetaxel had effects on cytology, ascites status and PCI (7). We have also studied in vivo pharmacokinetics of docetaxel in 11 patients (25). Our study identified that docetaxel effectively penetrated the peritoneal nodules up to $1.47 \mathrm{~mm}$ in diameter. The area under the curve of docetaxel administered intraperitoneally was almost 13-27 times higher in the peritoneal cavity than systemic administration (26).

Cisplatin (cis-diamminedichloroplatinum-III) causes apoptotic cell death by formation of DNA adducts (27). Platin analogs enters the peritoneal nodules by simple diffusion and penetrates 1 or $2 \mathrm{~mm}$ (28). In the setting of CRS and HIPEC, Urano and coworkers (29) showed an excellent in vitro and in vivo thermal augmentation of intraperitoneal cisplatin as well. The combination of cisplatin with docetaxel is expected to be more effective than each one alone. Safety and efficacy are well defined. Cisplatin and docetaxel were selected for intraperitoneal chemotherapies in our study. The combination chemotherapy regimen would be expected to be more effective for PM in intraperitoneal treatment due to higher concentration and augmentation by heat.

Our previous results showed that the ascites formation and peritoneal free cancer cells were abolished and PCI levels were decreased with intraperitoneal-based BIPSC (7). More recently, Ishigami and his group (30) also reported that surgery could be possible in $65 \%$ of cases after response to bidirectional induction chemotherapy with paclitaxel and S-1. The Phoenix-GC trial was designed to establish the superior effect of intraperitoneal chemotherapy over the systemic chemotherapy on survival, response rate and safety. However, this trial failed to show superiority in survival of intraperitoneal plus systemic chemotherapy to standard systemic chemotherapy (8). In contrast to this trial result, Zhao and his colleagues (31) identified that survival was significantly longer in multi-modality treatment group compared to systemic chemotherapy group.

Diagnostic laparoscopy is an important diagnostic tool to select patients who have a disease treatable by surgery 
and to demonstrate the cytology positivity in advanced GC patients (32). Adding HIPEC to laparoscopy converts the diagnostic tool to the therapeutic tool at the same time. LHIPEC is also useful for alleviation of malignant ascites (33-35). Ascites and free peritoneal cancer cells were completely abolished in all our cases with initiation of induction therapy using LHIPEC.

We selected three cycles of bidirectional chemotherapy for our clinical study. It is possible that repeating intraperitoneal chemotherapy more than four times could increase the risk of intraabdominal complications such as fistula, adhesions and intestinal obstruction.

There are some limitations of this study. (I) This study has been presented in the form of an observational retrospective study. Therefore, selection bias may be present in this study. Our future goal should be to perform this study with a larger and more structured prospective international collaborative randomized controlled trial. (II) A third arm needs to be added as systemic chemotherapy alone for internal control without induction chemotherapy. (III) Sample size of this study is not adequate to draw final conclusions.

\section{Conclusions}

The combination of intraoperative HIPEC with CRS after response to induction LHIPEC chemotherapy may offer superior clinical management favoring their postoperative recovery, a low incidence of complications and improved survival. The best outcomes can be expected with optimal cytoreduction and limited peritoneal dissemination after response to induction chemotherapy. Therefore, highly selected patients with PM of GC seem to be essential to perform conversion surgery with HIPEC safely and with acceptable mortality and morbidity. Limited survival and dismal prognosis in patients with PM of GC requires comprehensive multimodality treatment plans in order to improve the prognosis and survival.

\section{Acknowledgments}

We would like to acknowledge with gratitude, the endless support of Yutaka Yonemura.

Funding: None.

\section{Footnote}

Provenance and Peer Review: This article was commissioned by the Guest Editors (Paul H. Sugarbaker and Kurt Van der Speeten) for the focused issue "Intraperitoneal Chemotherapy for Peritoneal Metastases: HIPEC, EPIC, NIPEC, PIPAC and More" published in fournal of Gastrointestinal Oncology. This article has undergone external peer review.

Reporting Checklist: The authors have completed the STROBE Checklist. Available at http://dx.doi. org/10.21037/jgo-20-121

Conflicts of Interest: All authors have completed the ICMJE uniform disclosure form (available at http://dx.doi. org/10.21037/jgo-20-121). The focused issue was sponsored by the Peritoneal Surface Oncology Group International (PSOGI). The authors have no other conflicts of interest to declare.

Ethical Statement: The authors are accountable for all aspects of the work in ensuring that questions related to the accuracy or integrity of any part of the work are appropriately investigated and resolved. The study was conducted in accordance with the Declaration of Helsinki (as revised in 2013). The study was approved by institutional ethics board of Biruni University and informed consent was taken from all the patients.

Open Access Statement: This is an Open Access article distributed in accordance with the Creative Commons Attribution-NonCommercial-NoDerivs 4.0 International License (CC BY-NC-ND 4.0), which permits the noncommercial replication and distribution of the article with the strict proviso that no changes or edits are made and the original work is properly cited (including links to both the formal publication through the relevant DOI and the license). See: https://creativecommons.org/licenses/by-nc-nd/4.0/.

\section{References}

1. Thomassen I, van Gestel YR, van Ramshorst B, et al. Peritoneal carcinomatosis of gastric origin: a populationbased study on incidence, survival and risk factors. Int J Cancer 2014;134:622-8.

2. Ikeguchi M, Oka A, Tsujitani S, et al. Relationship between area of serosal invasion and intraperitoneal free cancer cells in patients with gastric cancer. Anticancer Res 1994;14:2131-4.

3. AJCC. Stomach Cancer. In Edge S, Byrd D, Campton 
C, et al. Cancer Staging Manual, 7th Edition. New York: Springer, 2010:117-26.

4. Sugarbaker PH, Yonemura Y. Clinical pathway for the management of resectable gastric cancer with peritoneal seeding: best palliation with a ray of hope for cure. Oncology 2000;58:96-107.

5. Sugarbaker PH. Peritoneal Carcinomatosis. Principals of Management. Boston: Kluwer Academic Publishers, 1996:359-74.

6. Yang XJ, Huang CQ, Suo T, et al. Cytoreductive surgery and hyperthermic intraperitoneal chemotherapy improves survival of patients with peritoneal carcinomatosis from gastric cancer: final results of a phase III randomized clinical trial. Ann Surg Oncol 2011;18:1575-81.

7. Canbay E, Mizumoto A, Ichinose M, et al. Outcome data of patients with peritoneal carcinomatosis form Gastric origin treated by strategy of Bidirectional Chemotherapy Prior to Cytoreductive surgery and Hyperthermic Intraperitoneal Chemotherapy in a single specialized center in Japan. Ann Surg Oncol 2014;21:1147-52.

8. Ishigami H, Fujiwara $\mathrm{Y}$, Fukushima R, et al. Phase III trial comparing intraperitoneal and intravenous paclitaxel plus $S 1$ versus cisplatin plus $S 1$ in patients with gastric cancer patients with peritoneal metastasis: PHOENIX-GC trial. J Clin Oncol 2018;36;1922-9.

9. Jacquet P, Sugarbaker PH. Clinical research methodologies in diagnosis and staging of patients with peritoneal carcinomatosis. Cancer Treat Res 1996;82:359-74.

10. Yonemura Y, Canbay E, Endou Y, et al. Comprehensive treatment for the peritoneal metastasis from gastric cancer. World J Surg Proced 2015;5:187-97.

11. Yonemura $Y$, Ishibashi H, Hirano $M$, et al. Effects of Neoadjuvant Laparoscopic Hyperthermic Intraperitoneal Chemotherapy and Neoadjuvant Intraperitoneal/Systemic Chemotherapy on Peritoneal Metastases from Gastric Cancer. Ann Surg Oncol 2017;24:478-85.

12. Shimada S, Tanaka E, Marutsuka T, et al. Extensive intraoperative peritoneal lavage and chemotherapy for gastric cancer patients with peritoneal free cancer cells. Gastric Cancer 2002;5:168-72.

13. Songun I, Putter H, Kranenbarg EM, et al. Surgical treatment of gastric cancer: 15 -year follow-up results of the randomised nationwide Dutch D1D2 trial. Lancet Oncol 2010;11:439-49.

14. Sugarbaker PH. Peritonectomy procedures. Ann Surg 1995;221:29-42.

15. Yonemura Y, Fujimura T, Fushida S, et al. Peritonectomy as a treatment modality for patients with peritoneal dissemination from Gastric Cancer. In: Nakajima T, Yamaguchi T (eds). Multimodality Therapy for Gastric Cancer. Tokyo: Springer Japan, 1999:71-80.

16. Van der Speeten K, Stuart OA, et al. Pharmacokinetic study of perioperative intravenous Ifosfamide. Int J Surg Oncol 2011;2011:185092.

17. Therasse P, Arbuck SG, Eisenhauer EA, et al. New guidelines to evaluate the response to treatment in solid tumors. European Organization for Research and Treatment of Cancer, National Cancer Institute of the United States, National Cancer Institute of Canada. J Natl Cancer Inst 2000;92:205-16.

18. Clavien PA, Barkun J, de Oliveira ML, et al. The ClavienDindo classification of surgical complications: five-year experience. Ann Surg 2009;250:187-96.

19. Common Terminology Criteria for Adverse Events (CTCAE) v5.0 in National Cancer Institute; Cancer Therapy Evaluation Program. Available online: https:// ctep.cancer.gov/protocolDevelopment/electronic_ applications/ctc.htm

20. Zurleni T, Gjoni E, Altomare M, et al. Conversion surgery for gastric cancer patients: A review. World J Gastrointest Oncol 2018;10:398-409.

21. Rudloff U, Langan RC, Mullinax JE, et al. Impact of maximal cytoreductive surgery plus regional heated intraperitoneal chemotherapy (HIPEC) on outcome of patients with peritoneal carcinomatosis of gastric origin: results of the GYMSSA trial. J Surg Oncol 2014;110:275-84.

22. Wagner AD, Syn NL, Moehler M, et al. Chemotherapy for advanced gastric cancer. Cochrane Database Syst Rev 2017;8:CD004064.

23. Ishigami $S$, Natsugoe $S$, Nakajo A, et al. Salvage gastrectomy following a combination of biweekly paclitaxel and S-1 for stage IV gastric cancer. J Gastrointest Surg 2008;12:1370-5.

24. Okabe H, Ueda S, Obama K, et al. Induction chemotherapy with S-1 plus cisplatin followed by surgery for treatment of gastric cancer with peritoneal dissemination. Ann Surg Oncol 2009;16:3227-36.

25. Yonemura Y, Canbay E, Sako S, et al. Pharmacokinetics of docetaxel during hyperthermic intraperitoneal chemotherapy for peritoneal metastasis. Gan To Kagaku Ryoho 2014;41:2496-9.

26. de Bree E, Rosing H, Beijnen JH, et al. Pharmacokinetic study of docetaxel in intraoperative hyperthermic i.p. chemotherapy for ovarian cancer. Anticancer Drugs 2003;14:103-10.

27. Cepeda V, Fuertes MA, Castilla J, et al. Biochemical 
mechanisms of cisplatin cytotoxicity. Anticancer Agents Med Chem 2007;7:3-18.

28. Los G, Mutsaers PH, Lenglet WJ, et al. Platinum distribution in intraperitoneal tumors after intraperitoneal cisplatin treatment. Cancer Chemother Pharmacol 1990;25:389-94.

29. Urano M, Kahn J, Kenton LA. The effect of cisdiamminedichloroplatinum (II) treatment at elevated temperatures on murine fibrosarcoma, FSa-II. Int J Hyperthermia 1990;6:563-70.

30. Ishigami H, Yamaguchi H, Yamashita H, et al. Surgery after intraperitoneal and systemic chemotherapy for gastric cancer with peritoneal metastasis or positive peritoneal cytology findings. Gastric Cancer 2017;20:128-34.

31. Zhao L, Li J, Bai C, et al. Multi-Modality Treatment for Patients With Metastatic Gastric Cancer: A Real-World Study in China. Front Oncol 2019;9:1155.

32. Badgwell B, Cormier JN, Krishnan S, et al. Does

Cite this article as: Canbay E, Canbay Torun B, Cosarcan K, Altunal C, Gurbuz B, Bilgic C, Sezgin C, Kaban KK, Yilmaz S, Yazici Z. Surgery with hyperthermic intraperitoneal chemotherapy after response to induction chemotherapy in patients with peritoneal metastasis of gastric cancer. J Gastrointest Oncol 2021;12(Suppl 1):S47-S56. doi: 10.21037/ jgo-20-121 neoadjuvant treatment for gastric cancer patients with positive peritoneal cytology at staging laparoscopy improve survival? Ann Surg Oncol 2008;15:2684-91.

33. Facchiano E, Scaringi S, Kianmanesh R, et al. Laparoscopic hyperthermic intraperitoneal chemotherapy (HIPEC) for the treatment of malignant ascites secondary to unresectable peritoneal carcinomatosis from advanced gastric cancer. Eur J Surg Oncol 2008;34:154-8.

34. Patriti A, Cavazzoni E, Graziosi L, et al. Successful palliation of malignant ascites from peritoneal mesothelioma by laparoscopic intraperitoneal hyperthermic chemotherapy. Surg Laparosc Endosc Percutan Tech 2008;18:426-8.

35. Valle M, Van der Speeten K, Garofalo A. Laparoscopic hyperthermic intraperitoneal peroperative chemotherapy (HIPEC) in the management of refractory malignant ascites: A multi-institutional retrospective analysis in 52 patients. J Surg Oncol 2009;100:331-4. 